\title{
Remote Sensing, Crop Yield Estimation and Agricultural Vulnerability Assessment: a Case of Southern Alberta
}

\author{
Xiaomeng Ren ${ }^{1}$, Wei Xu ${ }^{1, *}$ and Anne Smith ${ }^{2}$ \\ ${ }^{I}$ Department of Geography, University of Lethbridge, Lethbridge, AB, Canada \\ ${ }^{2}$ Agriculture and Agri-Food Canada, Research Centre, Lethbridge, AB, Canada
}

\begin{abstract}
This research investigates the relationship between agricultural production and the occurrence of meteorological droughts over time. A remote sensing approach is developed to estimate the yield of cereal crops based on the remotely sensed data in the study area. The yield estimates from remotely sensed imageries provide a primary data source to measure agricultural well-being and quantify agricultural vulnerability to drought. The drought condition as the stressor to agricultural production systems is characterized using the standard precipitation index (SPI). The results of the study indicate that crop production system in Southern Alberta is very vulnerable to drought. About half of the study area is associated with a high to extremely high vulnerability. If the drought trend in the recent past repeats itself in the near further, it can be expected that crop production in these areas will be seriously threatened.
\end{abstract}

Keywords: Agricultural vulnerability, drought, remote sensing, crop yield.

\section{INTRODUCTION}

Agricultural systems constitute a pivotal economic sector in rural Canada and worldwide. Sustainable rural systems are very much dependent upon the healthy development of agriculture. As a multi-faceted biophysical and socio-economic system, the agricultural system is heavily affected by variations and changes in climate conditions. Extreme climatic events such as severe drought can often cause devastating damages to agriculture and consequently to rural communities.

This research attempts to investigate the relationship between agricultural production and the occurrence of meteorological droughts over time, and consequently to examine how sensitive and vulnerable agricultural production is, given the variability in climate conditions in Southern Alberta. A remote sensing approach will be developed to estimate the yields of cereal crops in selected years based on remotely sensed data in the study area. The yield estimates based on the remote sensing approach will provide a primary data source to measure agricultural well-being and quantify agricultural vulnerability to drought.

\section{LITERATURE REVIEW}

The concept of vulnerability often refers to as "a potential of loss" [1,2]. It is widely accepted in the literature that vulnerability reflects the interaction between the stresses or disturbances, which arise outside and/or inside the system, and the system's inherent capacity to respond. Agricultural vulnerability to drought can then be understood as the potential loss of agricultural sectors or communities to dry

*Address correspondence to this author at the Department of Geography, University of Lethbridge, Lethbridge, AB, Canada; Tel: 1-403-3324561;

Fax: 1-403-3292016; E-mail: wei.xu@uleth.ca climatic conditions. For vulnerability assessment, vulnerability may be considered as a function of three components: sensitivity, adaptive capacity and exposure [3-6]. However, quantifying vulnerability can be quite difficult due to the complexity of the system under analysis and the fact vulnerability is not a directly observable phenomenon [7-9]. The traditional approach of quantifying vulnerability is primarily based on summing or averaging a set of weighted indicators that are indicative of vulnerability components. The indicators are always the directly observable or measurable conditions of the systems' elements and/or the characteristics of the disturbances that the system is exposed to. This method has been used to assessing vulnerability of both ecosystems and societies to different disturbances such as natural hazards, environmental changes, and pollution [10-15]. The main drawback of this approach is that the value of weighting factors depends to a great extent upon arbitrary decisions, and this reduces the confidence of such weighting methods [14].

Luers et al. developed a new measure for quantifying vulnerability of a system [8]. The proposed vulnerability metric measures sensitivity as the absolute value of the derivative of well-being with respect to the stressor, exposure as probability of the occurrence of stressor, and adaptive capacity as difference in the vulnerability under existing conditions and under the less vulnerable condition to which the system could potentially shift. In the case study, they investigated the vulnerability of agriculture system in a subtropical irrigated area of Mexico [8]. Well-being was captured by agricultural yields, while the stress of concern was night time temperature. It is suggested that this generalized function could also be used to examine the vulnerability of many other systems and/or places in response to various types of stresses. 
Remote sensing data have been widely applied to many research problems and practical applications, including meteorology, geology, canopy and soil investigations, ocean research, water management, and environmental monitoring [16]. Compared to the traditional data collection methods, the capability of remote sensing techniques of providing timely information over a large spatial extent at a wide range of spatial, temporal, and spectral resolutions is appreciated by numerous users in different application fields [17-19].

Agriculture is one of the major users of remote sensing data (Moulin et al., 1998). Numerous research efforts have been devoted to seeking a quantitative relation between remotely sensed spectral information and crop yields, and consequently obtaining a robust estimation and forecasting for agricultural productions [8, 20-33].

There are generally two main types of strategies used in the literature for estimating crop yields based on remote sensing data $[16,18]$. The first one is based on crop growth models, which incorporates remote sensing data into agrometeorological or bio-physiological models [23, 18, 31-33]. For example, Doraiswamy et al. (2003) implemented the real-time assessment of the magnitude and variation of crop condition parameters into the crop model called Erosion Productivity Impact Calculator (EPIC) [34]. The EPIC model was used to estimate crop yields at regional and state levels. Abou-Ismail et al. (2004) developed a rice yield estimation model by combining a rice growth simulation model with remote sensing data [35]. This method is considered capable in describing the complexity of plant-physiology, and is suitable at a field scale [18]. Ferencz et al. (2004) summarized several main drawbacks of this method: 1) the number of input parameters required for the agrometeorological or bio-physiological models is always considerably large, 2) it needs sufficient ground reference information which is expensive to collect, and 3) the models can be quite complex [16].

Another commonly used method is to empirically relate the remote sensing data to crop yields at a local or regional scale. These types of relations are always investigated based on the use of some indices generated from remotely sensed imagery. For example, Dadhwal and Sridhar (1997) investigated the relationship of a near-infrared (NIR)/red radiance ratio with wheat yield using a regression model [36]. The relationship was then used for wheat yield estimation. In a study by Ferencz et al. (2004), a new vegetation index, called the General Yield Unified Reference Index (GYURI)), was proposed which uses a fitted double-Gaussian curve to NOAA AVHRR data during the vegetation growth period. The regression models were established for different crop types to estimate crop yields [16]. Although the relationship found between the remote sensing data and crop yield from these empirical analyses may only have a local or regional value, such an approach is still preferred by many researchers as it is simple and can be achieved without any background physiological knowledge [37-39].

One of the primary variables used in modeling the relationship between remotely sensed information and crop yield is the vegetation index. Various vegetation indices have been generated from optical satellite sensors which can provide quantitative information about vegetation health and biomass [39-42]. One of the most commonly used vegetation indices for yield estimation is the normalized difference vegetation index (NDVI).

The NDVI is deduced from the physiological fact that "Chlorophyll a and b in the palisade layer of healthy green leaves absorbs most of the incident red radiant flux while the spongy mesophyll leaf layer reflects much of the near-infrared radiant flux" [43, p. 7]. The NDVI reflects the relationship between the amount of healthy green vegetation and the spectral reflectance of near-infrared and red wavelengths, and therefore can be used as a measure of ground green vegetation health and volume.

In the literature, through the use of simple regression or multiple regression analysis, correlations between NDVI and crop yield can be derived and used in yield estimation models for different vegetation types (corn, wheat, sugar beets, cotton, canola and grass) in various regions [37, 38, 44-46]. It is found the suitability of NDVI for yield estimation varies depending upon the acquisition time of the remote sensing images [37, 38, 47]. Several studies have discovered that the optimal image acquisition time for the best correlation between NDVI and crop yield is late July, particularly in western Canada [37, 38].

In summary, it can be concluded that vulnerability of a system or a place can be quantified by simplifying a complex system as a pair or pairs of interacting well-being and stresses, although a comprehensive quantitative vulnerability assessment is difficult. The reviewed works suggest that the empirical regression relationship between NDVI and crop yield is valuable for yield estimation modeling at a regional. Coupled with drought indices such as standardized precipitation index, it is possible to derive a sound understanding of crop production vulnerability to drought at a regional scale.

\section{STUDY AREA AND DATA}

This study is concerned with agricultural production in Southern Alberta (Fig. 1). The spatial extent of the Landsat TM scenes defines the boundary of the actual study area within which agricultural vulnerability assessment is conducted using remotely sensed data. This area represents the majority of agricultural regions in Southern Alberta.

As Canada's second largest agricultural producer and exporter, Alberta accounted for $21 \%$ of Canadian farm cash receipts from agriculture, and the farm cash receipts totaled $\$ 7.9$ billion in 2005 . In total, Alberta's agri-food exports were $\$ 5$ billion in 2005. Crop production and livestock are the two dominant sectors in Alberta agriculture [48]. Total Alberta farmland area was 52.1 million acres, with an average farm size of 970 acres. The dominant crops in the study area include wheat, barley, oats and rye. During the past decade, Alberta produced $28 \%$ of the nation's wheat crop, $44 \%$ of the barley, and $23 \%$ of the oats [48].

To assess agricultural vulnerability to drought at a detailed level, remotely sensed imageries are employed in the empirical analysis. The years of 1998, 1999 and 2001 are selected as the years that provide a representative variation in precipitation conditions. Since multi-date satellite imagery can often generate superior land use and cover classification accuracy, and consequently generate better yield estimation, two Landsat TM/ETM+ images for each selected year are acquired. The determination of image date is mainly re- 


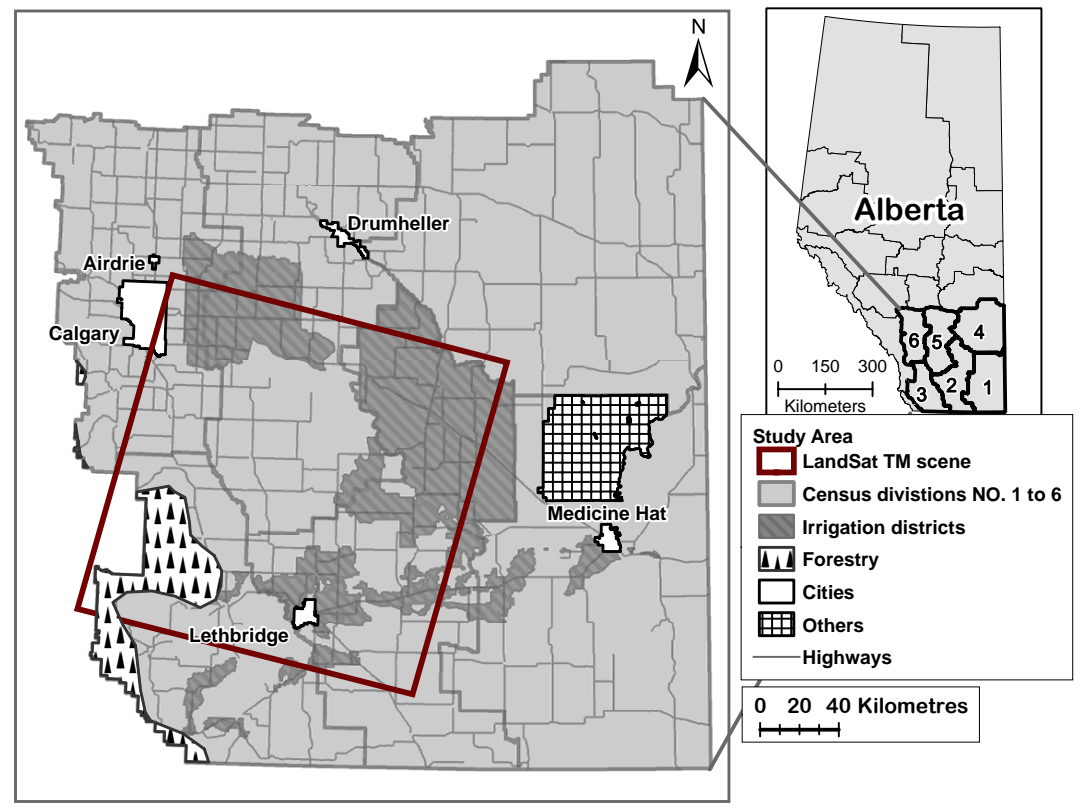

Fig. (1). Study Area: Southern Alberta, Canada.

stricted by data availability: 1) the temporal resolution (the time between two overpass dates for a particular location) of Landsat satellite sensor is 16 days; and 2) large cloud coverage prevents some images from being usable. The study area is defined as the overlapping area covered by all six acquired Landsat TM/ETM+ scenes over path 41 and row 25 (Fig. 1). Each of the obtained imageries contains seven spectral bands of information. Six bands (band 1: 0.45-0.52 $\mu \mathrm{m}$; band 2: 0.52-0.60 $\mu \mathrm{m}$; band 3: 0.63-0.69 $\mu \mathrm{m}$; band 4: 0.76-0.90 $\mu \mathrm{m}$; band 5: $1.55-1.75 \mu \mathrm{m}$; and band 7: 2.08-2.35 $\mu \mathrm{m}$ ) have a spatial resolution of 30 meters for each spectral pixel, and one thermal band (band 6: 10.4-12.5 $\mu \mathrm{m}$ ) has a spatial resolution of 60 meters, which is excluded in the image analysis.

\section{METHOD}

The quantitative method for assessing vulnerability developed by Luers et al. (2003) is adopted to assess the agricultural vulnerability to drought in Southern Alberta. Vulnerability is defined as a function of three components: sensitivity, well-being state relative to its damage threshold, and exposure. Vulnerability of the agricultural system was calculated as:

$$
V_{i}=S_{i} \times \frac{1}{n} \sum_{i=1}^{n} \frac{Y_{i}}{Y_{o}} \times E_{i}
$$

where: $\mathrm{V}_{\mathrm{i}}$ is the vulnerability value for a specific year at a pixel $\mathrm{i} ; \mathrm{S}_{\mathrm{i}}$ is the system's sensitivity; $\mathrm{Y}_{\mathrm{i}}$ is the crop yield in the year of interest $\left(1998,1999\right.$ or 2001) are $Y_{0}$ is the average crop yield over the selected years (1998, 1999 and 2001); and $E_{i}$ is the system's exposure to stress.

The sensitivity of crop production is defined as the change in the system's well-being corresponding to a small change in stress. It is measured as the slope of regressing crop yield against standard precipitation index (SPI) value. The calculation of the SPI first requires fitting the long-term precipitation record for the interested location into an appropriate probability density function. This function is then transformed into a normal distribution, so that the mean of the distribution is zero [49]. SPI values above zero indicate wetter periods and values less than 0 indicate drier periods. The monthly precipitation data during the growing season between May to August for a period of 1964 to 2004 were used to derive the value of SPI for all Environment Canada weather stations within the study area.

The exposure is the frequency of occurrence that the stress in below a threshold level. It is measured by the frequency of occurrence that the value of standard precipitation index is below -1.0 (moderate drought).The crop yield estimates were derived using the remote sensing data. Two Landsat images, one early and one late growing season, for 1998, 1999 and 2001 were used to calculate NDVI. The relationship between NDVI value and the farm reported crop yield was modeled using regression analysis. The regression coefficients were then employed to estimate crop yields at the pixel level. Fig. (2) presents the methodological procedure employed in this study.

\section{RESULTS}

\section{Estimated Crop Yields}

Based on the developed methodological procedure (Fig. 2), the imageries from each year were first classified to identify crop types using a supervised classification method. The overall classification accuracies are $86.4 \%$ (1998), $83.7 \%$ (1999), and $81.0 \%$ (2001). Because the cereal crop yields are used as a measure of agricultural wellbeing in the following agricultural vulnerability assessment, a relatively high classification user accuracy of cereal crop classes is needed. The user accuracies for the cereal crop class are $94.7 \%$ (1998), $92.7 \%$ (1999), and 89.8\% (2001).

The NDVI value of the image areas classified as cereal crops is employed as a primary independent variable for yield estimation in the regression analysis. Roads, field edges and fallow areas are masked off. The log-transformed NDVI from the atmospherically corrected image shows an advantage in yield estimation. Multiple regression analyses are used for yield estimation. Variables such as field loca- 


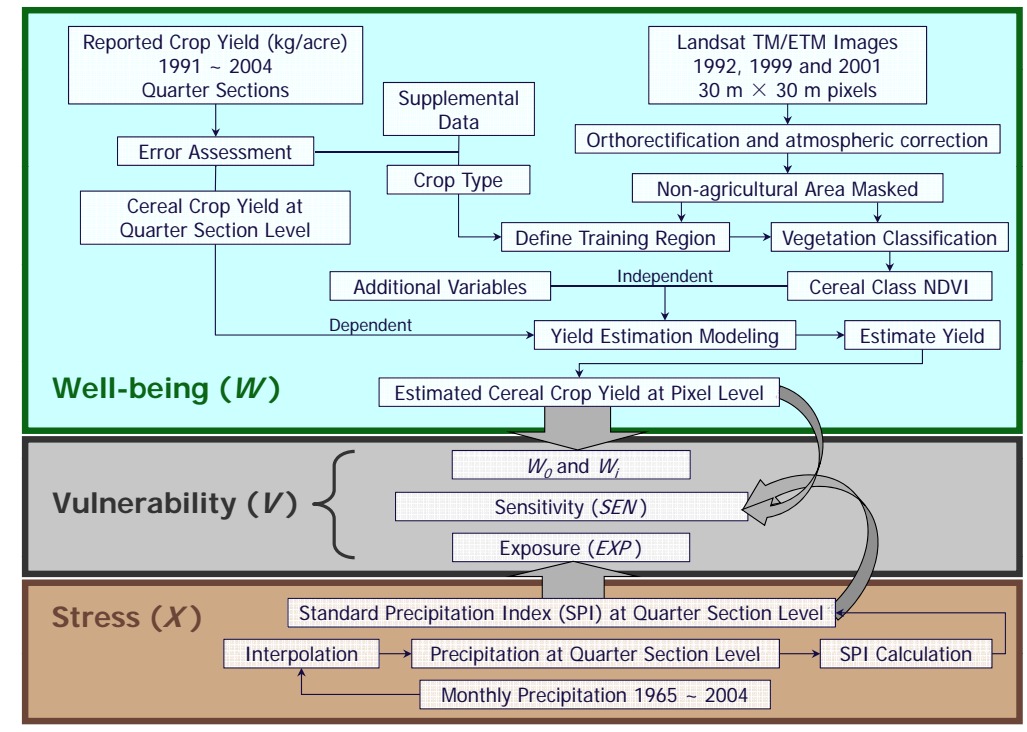

Fig. (2). Methodological procedure for agricultural volnerability assessment.

Table 1. Crop Yield Estimation Accuracies by Pixel Percentiles

\begin{tabular}{|c|c|c|c|c|c|c|c|c|c|c|c|c|}
\hline Year & $\mathbf{1 0 \%}$ & $\mathbf{2 0 \%}$ & $\mathbf{2 5 \%}$ & $\mathbf{3 0 \%}$ & $\mathbf{4 0 \%}$ & $\mathbf{5 0 \%}$ & $\mathbf{6 0 \%}$ & $\mathbf{7 0 \%}$ & $\mathbf{7 5 \%}$ & $\mathbf{8 0 \%}$ & $\mathbf{9 0 \%}$ & $\mathbf{M e d i a n}$ \\
\hline \hline 2011 & 23.8 & 52.8 & 59.1 & 63.0 & 69.8 & 75.9 & 81.8 & 86.5 & 89.2 & 91.3 & 95.2 & 76.0 \\
\hline 1999 & 57.5 & 69.3 & 72.8 & 75.8 & 80.0 & 83.8 & 87.6 & 90.6 & 92.1 & 93.7 & 96.8 & 83.7 \\
\hline 1998 & 50.6 & 66.0 & 70.0 & 73.4 & 78.3 & 82.0 & 86.0 & 89.7 & 91.3 & 93.3 & 96.6 & 82.0 \\
\hline
\end{tabular}

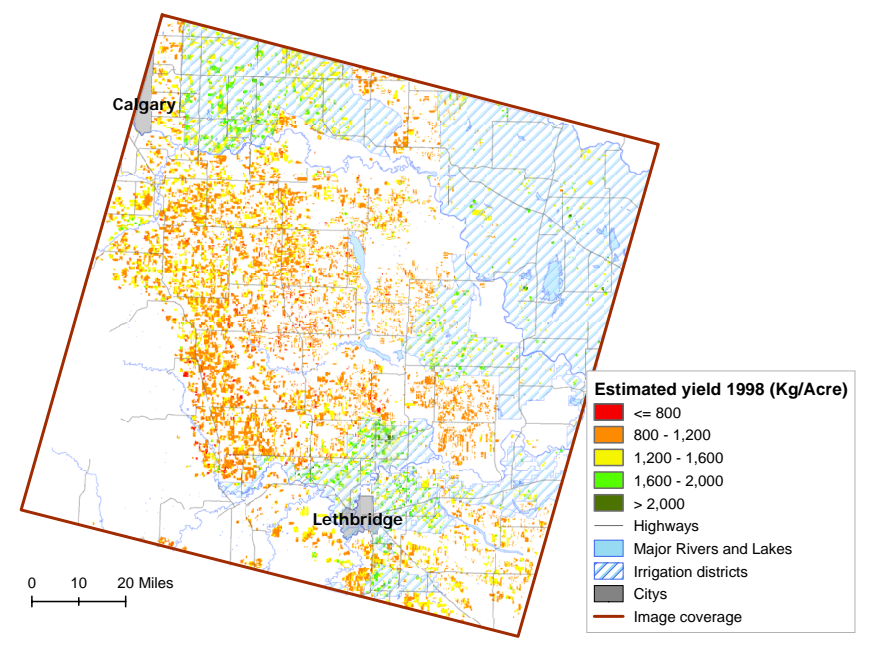

Fig. (3). Spatial distribution of estimated cereal crop yield, 1998.

tion, irrigation capacity and soil type are considered in the regression models in addition to the NDVI value. Nonsignificant variables are excluded step by step. Final yield estimation models for three years are all statistically significant at a 99\% confidence level. All independent variables in the models are also significant. The $\mathrm{R}^{2}$ values of the final yield estimation models are 0.336 (1998), 0.466 (1999), and 0.689 (2001). The regression residuals for all three models are normally distributed.

Table 1 presents in detail the pixel percentile distribution of crop yield estimation accuracies in 1998, 1999, and 2001 using the derived regression models. Overall, the 1999 crop model performs the best with an median accuracy of $83.7 \%$, while the 2001 regression model is the least accurate one with an median accuracy of $76.6 \%$.

These models are directly employed to generate yield maps of cereal crops at the image pixel level. These yield estimates are employed directly as a measure of agricultural wellbeing for assessing agricultural vulnerability in the region. As presented in the Figs. (3 and 4), the overall estimated yields of 1998 and 1999 are similar. The majority of the mapped area has a cereal crop yield of 800 to $1600 \mathrm{~kg} / \mathrm{acre}$. There were more areas associated with a higher yield (above $1600 \mathrm{~kg} / \mathrm{acre}$ ) in 1999 than those in 1998. 


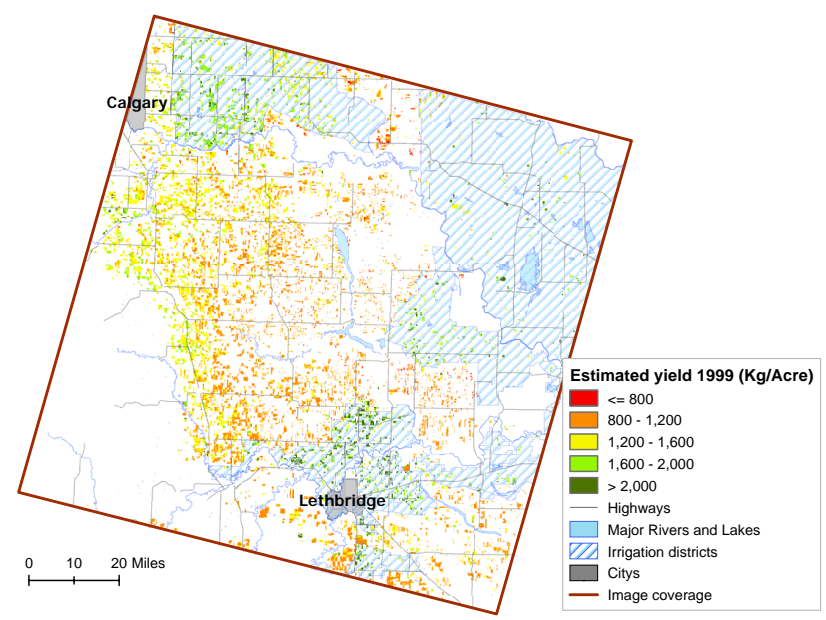

Fig. (4). Spatial distribution of estimated cereal crop yield, 1999.

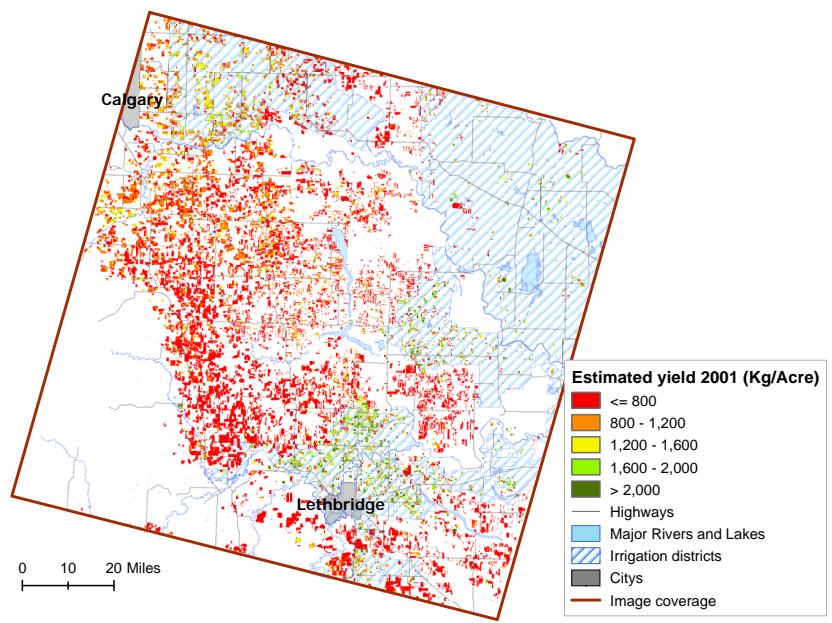

Fig. (5). Spatial distribution of estimated cereal crop yield, 2001.

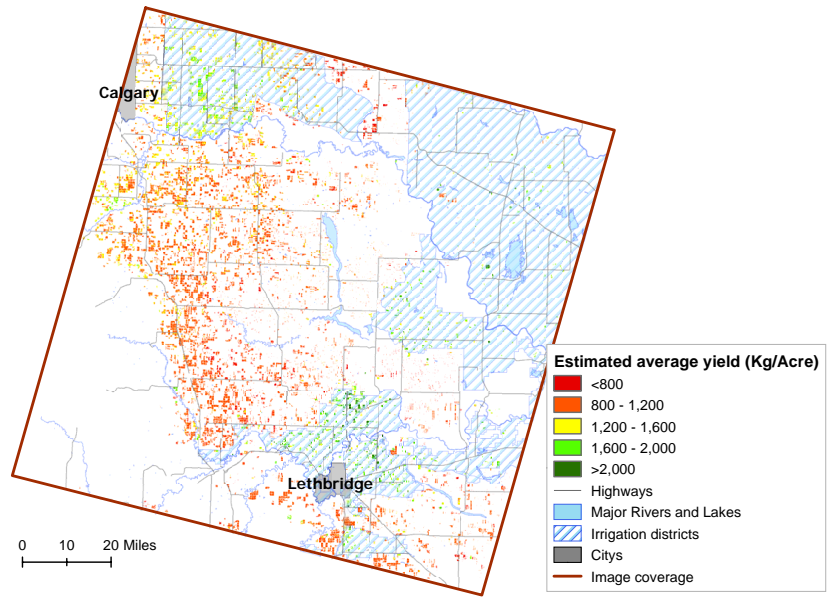

Fig. (6). Spatial distribution of average crop yield (1998, 1999, and 2001).

The estimated yield in 2001 (Fig. 5) was obviously lower than that in 1998 and 1999. Over 50\% of the mapped area in 2001 had a yield less than $800 \mathrm{~kg} /$ acre. Most of the areas in the southern irrigation districts maintained a high yield of above $1600 \mathrm{~kg} / \mathrm{acre}$ in all three years.
The average yield for the three years are calculated and mapped in Fig. (6). Table 2 presents the descriptive statistics of estimated average yields over three years. About $59.3 \%$ of the cereal crop field had an average yield between 800 to $1200 \mathrm{~kg} / \mathrm{acre}$. There were $10.89 \%$ of the cereal crop fields 
Table 2. Descriptive Statistics of Average Cereal Crop Yield (1998, 1999, and 2001)

\begin{tabular}{|c|c|c|}
\hline Yield range (kg/acre) & Percentage of Area & Mean (kg/acre) \\
\hline \hline$<800$ & $7.87 \%$ & 739 \\
\hline $800-1200$ & $59.30 \%$ & 990 \\
\hline $1200-1600$ & $21.94 \%$ & 1364 \\
\hline $1600-2000$ & $8.69 \%$ & 1763 \\
\hline$>2000$ & $2.20 \%$ & 2143 \\
\hline
\end{tabular}

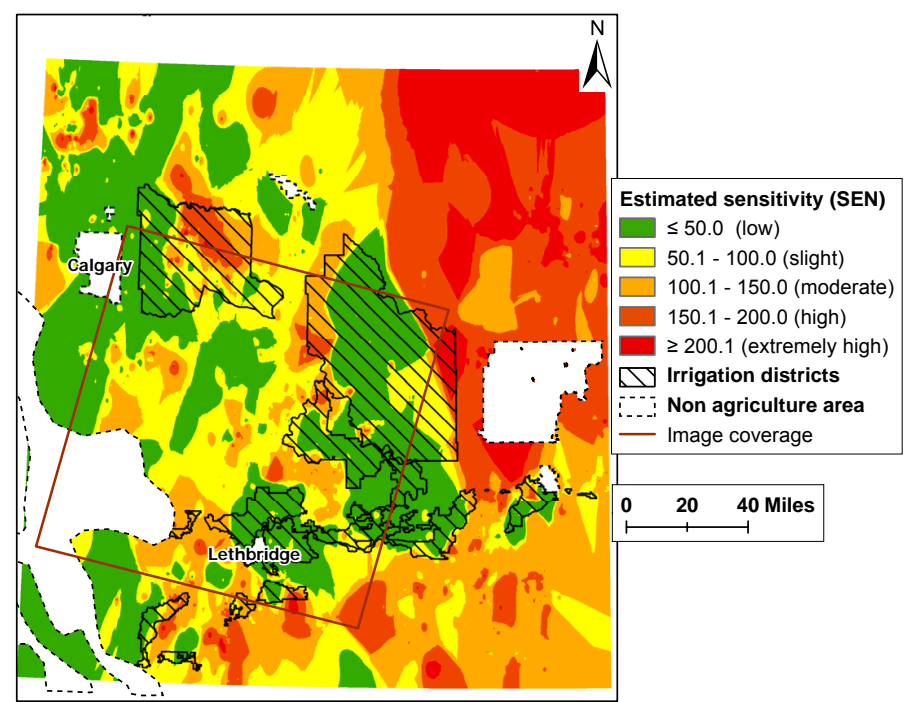

Fig. (7). Spatial distribution of crop production sensitivity to meteorological drought in growing season.

Table 3. Classes of Crop Production Sensitivity

\begin{tabular}{|c|c|c|c|c|}
\hline Sensitivity Classes & Sensitivity Value & Percentage Coverage & Mean & Standard Deviation \\
\hline \hline Low & $<50$ & $30.06 \%$ & -0.15 & 42.68 \\
\hline Slight & $50-100$ & $22.29 \%$ & 75.70 & 14.87 \\
\hline Moderate & $100-150$ & $22.45 \%$ & 122.75 & 13.82 \\
\hline High & $150-200$ & $16.64 \%$ & 219.01 & 14.81 \\
\hline Extremely high & $>200$ & $8.57 \%$ & 11.98 \\
\hline
\end{tabular}

that produce an average yield of more than $1600 \mathrm{~kg} / \mathrm{acre}$. Only $7.87 \%$ of the cereal crop fields had an average yield of less than $800 \mathrm{~kg} / \mathrm{acre}$. As expected, the irrigated regions were normally associated with higher average yields in the study area in the selected years.

\section{Estimated Sensitivity of Crop Yields}

The sensitivity of crop yield is estimated for the point data at the centroid locations of the quarter-sections. The point data is then interpolated to generate a continuous surface representation of crop production. The spatial distribution of sensitivity is presented in Fig. (7). The descriptive statistics for each sensitivity class are presented in Table $\mathbf{3}$. Over $30 \%$ of the study area has a sensitivity value less than 50. Most of the areas with a low sensitivity are located within or close to irrigation districts (See Fig. 7). Neverthless, there are some areas within irrigation districs that are estimated more sensitive than it is expected. This is because not all agricultural land within irrigation districts is actually irrigated every year. For example, the total area of the irrigation district east of Calgary (Western Irrigation District) is about half million acres, within which about 95,000 acres are contracted on the water role and only less than 55,000 acres actually requested for irrigation service in 2004 [49]. The southwest corner of the study area also has a low value of sensitivity. This is mostly non-agricultural areas with mountains and hills. Slight and moderate sensitive areas are at central longitude areas and the southeast of the study area. These two classes cover about $44 \%$ of the study area. Most of the central-east and northeast areas are classified as having a high to extremely high sensitivity. About $9 \%$ of the study area is associated with an extremely high sensitivity value. A small portion of the study area is associated with a negative sensitivity value. In these areas, agricultural production is more sensitive to the extremely wet condition rather than to the extreme dry condition might be. Due to the orientation and scope of this study, agricultural vulnerability to the extremely wet condition will not be discussed. 


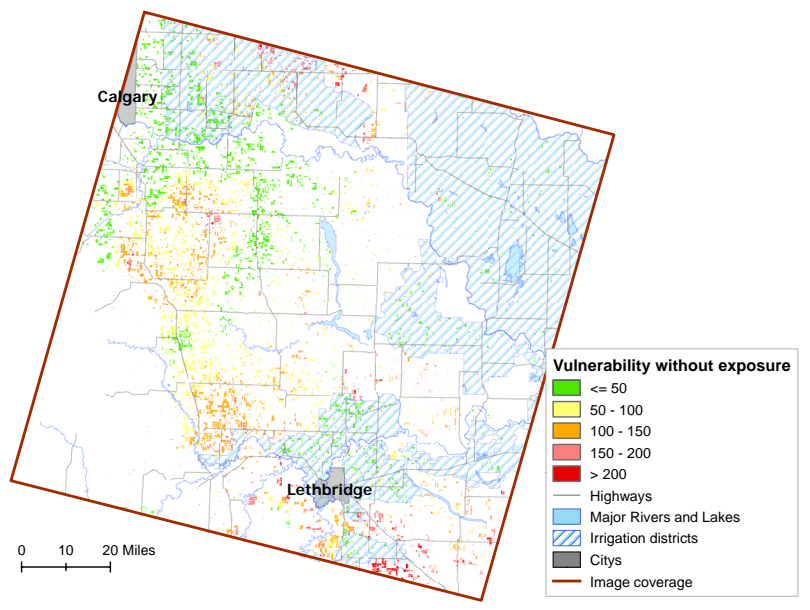

Fig. (8). Crop production vulnerability to meteorological drought (1998, 1999 and 2001), without considering exposure.

Table 4. Class of Crop Production Vulnerability, Without Considering Exposure

\begin{tabular}{|c|c|c|c|c|}
\hline Vulnerability Classes & Vulnerability Value & Percentage Coverage & Mean & Standard Deviation \\
\hline \hline Low & $<50$ & $34.72 \%$ & -5.34 & 223.04 \\
\hline Slight & $50-100$ & $28.42 \%$ & 76.27 & 14.50 \\
\hline Moderate & $100-150$ & $23.28 \%$ & 170.88 & 13.97 \\
\hline High & $150-200$ & $9.04 \%$ & 276.95 & 13.88 \\
\hline Extremely high & $>200$ & $4.54 \%$ & 632.45 \\
\hline
\end{tabular}

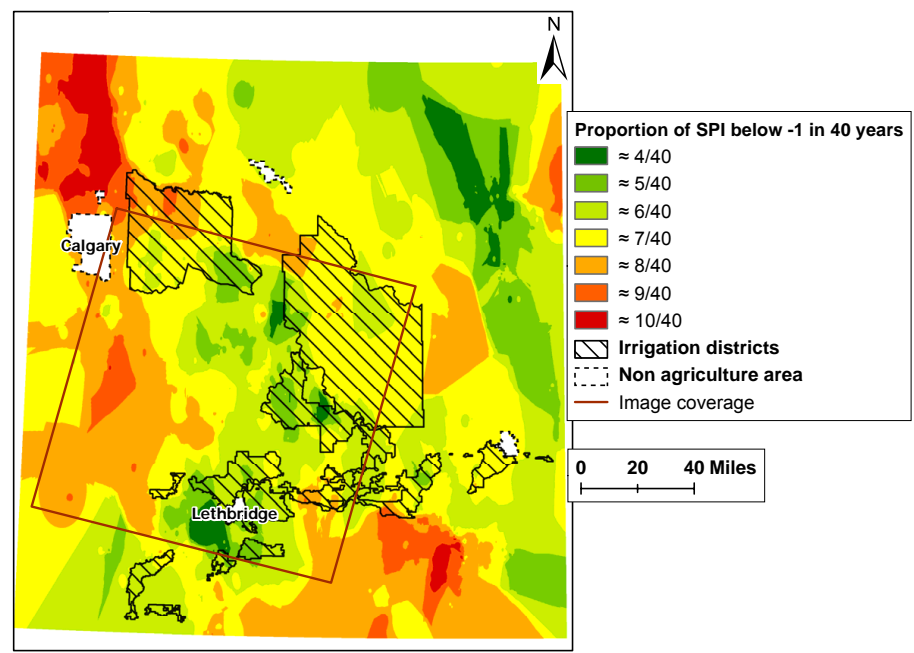

Fig. (9). Long-term exposure to moderate meteorological drought, 1965 to 2004.

\section{Crop Production Vulnerability to Drought}

Assuming that 1998, 1999, and 2001 can be considered as representative crop growth years, Fig. (8) presents the spatial pattern of crop production vulnerability using the three-year average of vulnerability. On average, over the selected three years, almost $35 \%$ of the study area was associated with a low vulnerability without considering exposure. The area with a low vulnerability was where a low sensitivity was estimated. The areas with a slight to moderate vulnerability value accounted for $51.7 \%$ of the study area. They were mainly located in the central part of the area. A total of $13.58 \%$ of study area was estimated with a high to extremely high vulnerability (Table 4).
Given the fact that a moderate drought might be harmful enough to cause severe damage to cereal crop production, crop production vulnerability to the moderate meteorological drought in the study area over a long run is assessed. The exposure to a moderate meteorological drought condition is calculated as the proportion of the year with the SPI value less than -1.0 during the period of 1965 to 2004 . The spatial distribution of the exposure is presented in Fig. (9). In the study area, at least four growing seasons were considered to be moderately dry during the period of 1965 to 2004. Over $80 \%$ of the study area experienced six to eight moderately dry growing seasons. The highest exposure to the moderate meteorological drought was 10 out of 40 years. 


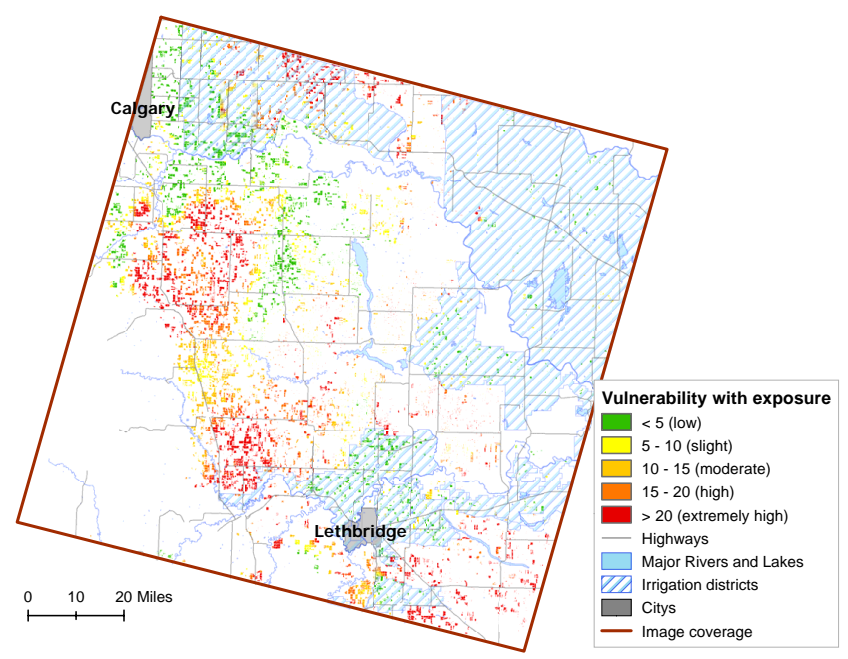

Fig. (10). Crop production vulnerability to moderate meteorological drought.

Table 5. Class of Crop Production Vulnerability to Moderate Meteorological Drought

\begin{tabular}{|c|c|c|c|c|}
\hline Vulnerability Classes & Vulnerability Value & Percentage Coverage & Mean & Standard Deviation \\
\hline \hline Low & $<5$ & $26.76 \%$ & -2.95 & 49.21 \\
\hline Slight & $5-10$ & $11.53 \%$ & 1.45 & 1.53 \\
\hline Moderate & $10-15$ & $14.79 \%$ & 12.54 & 1.42 \\
\hline High & $15-20$ & $16.67 \%$ & 28.50 & 1.42 \\
\hline Extremely high & $>20$ & $30.25 \%$ & 24 \\
\hline
\end{tabular}

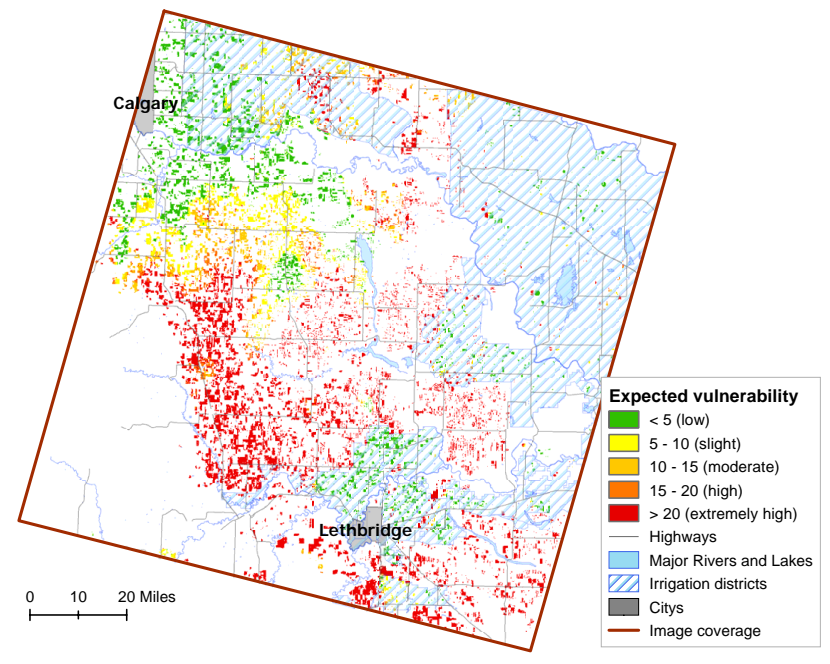

Fig. (11). Expected agricultural vulnerability to severe meteorological drought.

The spatial distribution of crop production vulnerability to the moderate meteorological drought condition is presented in Fig. (10). The descriptive statistics are presented in Table 5. A larger area was estimated as very vulnerable due to the higher occurrence of the moderate meteorological drought condition in the study area. A total of $46.92 \%$ of the study area was considered highly or extremely highly vulnerable to the moderate drought condition, particularly in the places outside of the irrigation districts. Only about a quarter of the study area was not vulnerable, most of which was within the boundary of the irrigation districts.
Given the increasing intensity of recent drought occurrence from 1990 to 2004, it is expected that the drought occurrence might be expected to be more frequent in the near future. Fig. (11) presents the expected vulenerability of cropy production to the extreme drought condition if the recent drought frequency takes place in the near future. About half of the study area is expected to be associated with a high to extremely vulnerability. The south part of the study area in the vicinity of Lethbridge is expected to be very vulnerable to increasing drought events in the near future if the drought trend in the recent past repeats. The irrigation sys- 
tems will make a difference. Because of the enhanced adaptive capacity in the irrigation districts, not only is the current agricultural vulnerability in the districts relatively low, but also agriculture production is expected to be less vulnerable to the drought condition even if the propensity of the drought increases in the near future.

\section{CONCLUSIONS}

Assessing agricultural vulnerability is fundamental to understand interactions between agricultural systems and their external stresses including climatic conditions. In this study, an existing analytical method to quantify vulnerability is adopted to assess the magnitude as well as the spatial pattern of agricultural vulnerability to drought conditions in Southern Alberta. Overall, the regions investigated in this study were susceptible to varying degrees of agricultural vulnerability to drought conditions.

Empirically, this study generates some valuable insights into the extent and spatial variation of agricultural vulnerability to drought condition in Southern Alberta. First, the findings from this research indicate that there is a sharp contrast in agricultural vulnerability to drought between irrigated districts and non-irrigated areas. While non-irrigated areas are vulnerable to varying drought conditions, irrigated agricultural areas are largely insensitive to droughts. Such findings confirm the importance of irrigation practices in the regions. The installation of irrigation systems in the region has certainly elevated the adaptive capacity of agriculture systems to cope with drought related disturbances in the study area. Overall, a large area is quite vulnerable to the moderate level drought. Although the moderate drought may not cause as devastating effects to agricultural production as those by severe drought, it can still result in an obvious reduction in crop yields in the region.

The empirical results presented in this paper also indicate that remote sensing data as well as the associated analytical approaches can be useful and powerful in assessing the spatial variability of agricultural vulnerability. Since the remotely sensed data are readily available at a relatively lower cost nowadays, such approaches can be frequently employed to assess the changing relationship between agricultural sectors and varying climate conditions in a timely manner.

\section{CONFLICT OF INTEREST}

The authors confirm that this article content has no conflicts of interest.

\section{ACKNOWLEDGEMENT}

Declared none.

\section{REFERENCES}

[1] Cutter SL, Vulnerability to environmental hazards. Prog Hum Geogr 1996; 20(4); 529-39.

[2] Cutter SL, Boruff BJ, Shirley WL. Social vulnerability to environmental hazards. Soc Sci Quart 2003; 84(2): 242-61.

[3] IPCC, Impacts, adaptation, and vulnerability climate change 2001, Third Assessment Report of the IPCC. University Press: Cambridge, UK 2001.

[4] Turner BL, Kasperson RE, Matson PA, et al. A framework for vulnerability analysis in sustainability science. Proc Natl Acad Sci USA 2003; 100(14); 8074-9. Radar Analysis of Range-Land Revegetation of a Mixed Prairie. J Range Manag 1994; 47(5): 385-91.

[18] Moulin S, Bondeau A, Delecolle R. Combining agricultural crop models and satellite observations: from field to regional scales. Int J Remote Sens 1998; 19(6): 1021-36.

[19] Bastiaanssen WGM, Molden DJ, Makin IW. Remote sensing for irrigated agriculture: examples from research and possible applications. Agri Water Manag 2000; 46(2): 137-55.

[20] Idso SB, Jackson RD, Reginato RJ. Remote-sensing for agricultural water management and crop yield prediction. Agric Water Manag 1977; 1(4): 299-10.

[21] Hatfield JL. Remote-sensing estimators of potential and actual crop yield. Remote Sens Environ 1983; 13(4): 301-11.

[22] Zhang RH. An improved model of crop yield estimate by remotesensing. Kexue Tongbao 1984; 29(2): 284-4.

[23] Bouman BAM. Crop Modeling and Remote-sensing for yield prediction. Netherlands J Agric Sci 1995; 43(2): 143-61.

[24] Sanchez-Arcilla A, Jimenez JA, Valdemoro HI. The Ebro delta: Morphodynamics and vulnerability. J Coastal Res 1998; 14(3): 754-72.

[25] Serrano L, Filella I, Penuelas J. Remote sensing of biomass and yield of winter wheat under different nitrogen supplies. Crop Sci 2000; 40(3): 723-31

[26] Shao Y, Fan XT, Liu H, et al. Rice monitoring and production estimation using multitemporal RADARSAT. Remote Sens Environ 2001; 76(3): 310-25.

[27] Labus MP, Nielsen GA, Lawrence RL, Engel R, Long DS. Wheat yield estimates using multi-temporal NDVI satellite imagery. Int J Remote Sens 2002; 23(20): 4169-80.

[28] Lobell DB, Asner GP. Comparison of earth observing-1 ALI and Landsat ETM+ for crop identification and yield prediction in Mexico. IEEE Trans Geosci Remote Sens 2003; 41(6): 1277-82.

[29] Lobell DB, Asner GP, Ortiz-Monasterio JI, Benning TL. Remote sensing of regional crop production in the Yaqui Valley, Mexico: estimates and uncertainties. Agric Ecosyst Environ 2003; 94(2): $205-20$. 
[30] Lobell DB, Ortiz-Monasterio JI, Asner GP, Naylor RL, Falcon WP. Combining field surveys, remote sensing, and regression trees to understand yield variations in an irrigated wheat landscape. Agron J 2005; 97(1): 241-9.

[31] Babar MA, van Ginkel M, Klatt A, Prasad B, Reynolds MP. The potential of using spectral reflectance indices to estimate yield in wheat grown under reduced irrigation. Euphytica 2006; 150(1-2): 155-72.

[32] Badarinath KVS, Chand TRK, Prasad VK. Agriculture crop residue burning in the Indo-Gangetic Plains - A study using IRS-P6 AWiFS satellite data. Curr Sci 2006; 91(8): 1085-9.

[33] Prasad AK, Chai L, Singh RP, Kafatos M. Crop yield estimation model for Iowa using remote sensing and surface parameters. Int $\mathbf{J}$ Appl Earth Obs Geoinf 2006; 8(1): 26-33.

[34] Doraiswamy PC, Moulin S, Cook PW, Stern A. Crop yield assessment from remote sensing. Photogramm Eng Remote Sensing 2003; 69(6): 665-74.

[35] Abou-Ismail O, Huang JF, Wang RC. Rice yield estimation by integrating remote sensing with rice growth simulation model. Pedosphere 2004; 14(4): 519-26.

[36] Dadhwal VK, Sridhar VN. A non-linear regression form for vegetation index-crop yield relation incorporating acquisition date normalization. Int J Remote Sens 1997; 18(6): 1403-8.

[37] Hochheim KP, Barber DG. Spring wheat yield estimation for Western Canada using NOAA NDVI data. Can J Remote Sens 1998; 24(0703-8992 ): 17-27.

[38] Basnyat P, McConkey B, Lafond GR, Moulin A, Pelcat Y. Optimal time for remote sensing to relate to crop grain yield on the Canadian prairies. Can J Plant Sci 2004; 84(1): 97-103.

[39] Bullock PR. A comparison of growing season agrometeorological stress and single-date Landsat NDVI for wheat yield estimation in west central Saskatchewan. Can J Remote Sens 2004; 30(1): 101-8.
[40] Muldavin EH, Neville P, Harper G. Indices of grassland biodiversity in the Chihuahuan Desert ecoregion derived from remote sensing. Conserv Biol Ser 2001; 15(4): 844-55.

[41] Zarco-Tejada PJ, Berjon A, Lopez-Lozano R, et al. Assessing vineyard condition with hyperspectral indices: Leaf and canopy reflectance simulation in a row-structured discontinuous canopy. Remote Sens Environ 2005; 99(3): 271-87.

[42] Beeri O, Peled A. Spectral indices for precise agriculture monitoring. Int J Remote Sens 2006; 27(9-10): 2039-47.

[43] Jensen JR. Introductory Digital Image Processing: A Remote Sensing Perspective. London: Pearson 2005.

[44] Ray SS, Pokharna SS, Ajai. Cotton yield estimation using agrometeorological model and satellite-derived spectral profile. Int $\mathrm{J}$ Remote Sens 1999; 20(14): 2693-702.

[45] Plant RE, Munk DS, Roberts BR, et al. Relationships between remotely sensed reflectance data and cotton growth and yield. Trans ASAE 2000; 43(3): 535-46.

[46] Seaquist JW, Olsson L, Ardo J. A remote sensing-based primary production model for grassland biomes. Ecol Modell 2003; 169(1) 131-55.

[47] Vicente-Serrano SM, Cuadrat-Prats JM, Romo A. Early prediction of crop production using drought indices at different time-scales and remote sensing data: application in the Ebro valley (North-East Spain). Int J Remote Sens 2006; 27(3): 511-8.

[48] Edwards DC, McKee TB. Development of a surface water supply index for the western United States, Climatology Report, F. Colorado State University: Collins, Colorado 1997.

[49] WID, Western Irrigation District Annual Report: Alberta, Canada, 2004, Available at: http://www.wid.net/AnnualReports/2004AnnRpt.pdf

Received: April 19, $2011 \quad$ Revised: April 23, $2011 \quad$ Accepted: April 23, 2012

(C) Ren et al.; Licensee Bentham Open.

This is an open access article licensed under the terms of the Creative Commons Attribution Non-Commercial License (http://creativecommons.org/licenses/by-nc/3.0/) which permits unrestricted, non-commercial use, distribution and reproduction in any medium, provided the work is properly cited. 